\title{
TITLE:
}

\section{DNA repair genes in the Megavirales pangenome}

$\operatorname{AUTHOR}(S)$ :

Blanc-Mathieu, Romain; Ogata, Hiroyuki

CITATION:

Blanc-Mathieu, Romain ...[et al]. DNA repair genes in the Megavirales pangenome. Current Opinion in Microbiology 2016, 31: 94-100

ISSUE DATE:

2016-06

URL:

http://hdl.handle.net/2433/210000

\section{RIGHT:}

(c) 2016. This manuscript version is made available under the CC-BY-NC-ND 4.0 license

http://creativecommons.org/licenses/by-nc-nd/4.0/; The full-text file will be made open to the public on 1 June 2017 in accordance with publisher's 'Terms and Conditions for Self-Archiving'.; この論文は出版社版でありません。引用の際に は出版社版をご確認ご利用ください。; This is not the published version. Please cite only the published version. 


\section{DNA repair genes in the Megavirales pangenome}

Romain Blanc-Mathieu ${ }^{1}$ and Hiroyuki Ogata ${ }^{1, *}$

${ }^{1}$ Bioinformatics Center, Institute for Chemical Research, Kyoto University, Gokasho, Uji,

Kyoto, Japan (R.B.M.: roblanc@kuicr.kyoto-u.ac.jp; H.O.: ogata@ kuicr.kyoto-u.ac.jp)

* Corresponding author: ogata@kuicr.kyoto-u.ac.jp

Short title: DNA repair genes in Megavirales 
Megavirales pangenome encodes key enzymes involved in five major DNA repair pathways.

Larger Megavirales genomes tend to encode more genes for DNA repair enzymes than smaller Megavirales genomes in consistence with Drake's rule. This suggests that these enzymes play a crucial role in maintaining the integrity of their large genomes.

A few DNA repair enzymes are inferred to be encoded in the last common ancestors of individual families in the order Megavirales, suggesting that they already had the potential to achieve a relatively large genome compared to extant DNA viruses lacking DNA repair genes.

Individual families of Megavirales gradually increased their genome size by acquiring new repair functions from their hosts through horizontal gene transfer. 


\begin{abstract}
The order "Megavirales" represent a group of eukaryotic viruses with a large genome encoding a few hundred up to two thousand five hundred genes. Several members of Megavirales possess genes involved in major DNA repair pathways. Some of these genes were likely inherited from an ancient virus world and some others were derived from the genomes of their hosts. Here we examine molecular phylogenies of key DNA repair enzymes in light of recent hypotheses on the origin of Megavirales, and propose that the last common ancestors of the individual families of the order Megavirales already possessed DNA repair functions to achieve and maintain a moderately large genome and that this repair capacity gradually increased, in a family-dependent manner, during their recent evolution.
\end{abstract}




\section{Introduction}

Nucleo-cytoplasmic large DNA viruses (NCLDVs) are a group of viruses that infect diverse members of eukaryotes and possess a large double-stranded DNA genome varying in size from $100 \mathrm{~kb}$ to $2.5 \mathrm{Mb}[1,2]$. They are considered to form a monophyletic group based on the conservation of several genes [3], which led to the recent proposal of the order "Megavirales" to refer to this viral group [4].

Microbiologists and evolutionary biologists have investigated the evolution of Megavirales genes by sequence and molecular phylogenetic analyses and proposed theories on the origin of Megavirales and its association with the emergence of eukaryotes [5-9]. Depending on hypotheses, Megavirales genes can have different origins. A recent hypothesis postulates that Megavirales evolved from ancient DNA transposons of the Polintons family that are themselves the remnant of Tectoviridae-like bacteriophages that entered the protoeukaryotic cell along with the Alphaproteobacterial endosymbiont $[6,10]$. Under this scenario, Megavirales are the product of a "melting pot" of early viral evolution and part of their genes were directly derived from an ancient virus world as "hallmark viral genes" [11]. Alternatively, Megavirales genes can be acquired from known cellular organisms including viral hosts ("the accretion hypothesis") [12-14], or could have been vertically inherited from unknown and ancestral cellular organisms ("the reductive evolution from the fourth (or more) domain(s) hypothesis") [5,15]. These scenarios are not totally exclusive of each other. For instance, an ancient cellular organism might have 
evolved to an ancestor of Megavirales by reductive genome evolution, followed by later reaccumulation of cellular genes in the course of viral evolution.

One of the notable features uncovered from the genomics of Megavirales is that some members abundantly encode DNA repair genes in their genomes [16,17]. DNA repair functions are essential for cellular organisms (i.e., "large genomes") but are infrequent or absent in smaller viral genomes. Certain DNA repair enzymes are known to be specific to a subset of Megavirales members having a particularly large genome [18]. Therefore, Megavirales DNA repair genes are of interest to understand the evolution of their large genomes. In this manuscript, we review the homologs of key DNA repair genes in the pangenome of Megavirales with a special focus on their phylogenetic relationships with eukaryotic homologs.

\section{Classification of Megavirales}

The order Megavirales is currently composed of seven families: Mimiviridae, Marseilleviridae, Phycodnaviridae, Poxviridae, Asfarviridae, Iridoviridae and Ascoviridae [4]. Following Santini and colleagues [19], instead of Mimiviridae, we used the term "Megaviridae" family which includes viruses classified in Mimiviridae plus Phaeocystis globosa virus (PgV), Cafeteria roenbergensi virus (CroV), Organic lake phycodnaviruses (OLPV1 and 2), Aureococcus anophagefferens virus (AaV) [20] and Chrysochromulina ericina virus $(\mathrm{CeV})[21]$. The recent discoveries of pandoraviruses (1.9 $\mathrm{Mb} \sim 2.5 \mathrm{Mb}$; [22,23]), Mollivirus sibericum (650 kb, [24]), Pithovirus sibericum (610 kb, [25]), substantially expanded the known diversity of Megavirales lineages [26,27]. These viruses 
wait for their official taxonomic classifications; a phylogenetic analysis suggests that pandoraviruses are a group of viruses belonging to the Phycodnaviridae family [2].

\section{Why do Megavirales genomes encode many DNA repair genes?}

There are five known DNA repair pathways: the base excision repair (BER), nucleotide excision repair (NER), double-strand break (DSB) repair, mismatch repair (MMR), and direct damage reversal (DDR) pathways (Box 1). Most of the key enzymes in these DNA repair pathways can be found in the genomes of Megavirales (Table S1). Transcriptomic ([24,28-33]) and proteomic ([24,34-37]) studies revealed that many of these DNA repair genes are transcriptionally active during infection and that gene products (i.e., enzymes) are packaged into Megavirales virions (Table S1). Individual Megavirales genomes encode 0 up to 15 of those genes (3.6 genes on average). In contrast, other smaller double-stranded DNA viruses encode 0 to 5 of those genes ( 0.4 genes on average). Redrejo-Rodríguez and Salas provided a comprehensive review on the BER pathway genes in the pangenome of Megavirales [38]. Interestingly, members of the Megaviridae family, which possess a relatively large genome compared to the members of other families, encode the full or almost full set of genes needed to accomplish a viral BER pathway.

Microorganisms (viruses, prokaryotes and unicellular eukaryotes) with a larger genome tend to encode a larger number of genes than those with a smaller genome [39]. As a consequence, the target-size of deleterious mutation is greater for microorganisms with a larger genome. We thus expect a lower mutation rate per base per generation (i.e., a higher fidelity in replication and repair) for microorganisms with a larger genome than with a 
smaller genome. Drake postulated that the mutation rate per nucleotide site per generation scales inversely with genome size of DNA-based microorganisms and proposed that the microbial mutation rate per genome may have evolved towards a nearly invariant value across taxa [40]. Subsequent analyses demonstrated that most microorganisms with an estimated mutation rate per nucleotide site per generation conform to the inverse scaling observed by Drake $[41,42]$. There are currently no data available for the mutation rate for the viruses of Megavirales. However, in line with Drake's rule, the genome size positively correlates with the number of DNA repair genes in Megavirales (Spearman's $\rho=0.4, p=$

$1.7 \times 10^{-4}$ ) (Figure 1). Exceptions to this trend are the three pandoraviruses encoding only two of the known repair genes that we analyzed. Pandoraviruses may rely on host's DNA repair machinery or they may encode either highly divergent or unidentified DNA repair genes.

\section{DNA repair genes from an ancient virus world}

Previous phylogenetic analyses (see references in Table 1) suggested an old origin for some of the DNA repair genes encoded in the Megavirales pangenome, which may predate the radiation of major eukaryotic lineages. Most of DNA processing genes are not conserved across the three domains of life. Mre11/Rad50 are among the few DNA processing enzymes that are universally conserved in the three domains [43]. Based on this observation, some authors suggested that the last universal common ancestor (LUCA) was capable of processing DNA [44]. However, Forterre argues against this hypothesis based on the fact that majority of the core enzymes for DNA replication are not homologous between 
bacteria and eukaryote/archaea [45], and proposes that LUCA still had an RNA genome and that the descendant cellular lineages (leading to the three domains) acquired DNA processing enzymes including Mre11/Rad50 not from cellular organisms but from viruses [46]. Forterre's scenario assumes the existence of viral ancestors that possessed Mre11/Rad50 genes. Interestingly, some Megavirales members possess Mre11 and/or Rad50 homologs (Table S1). Among these, Acanthamoeba polyphaga mimivirus encodes a fused version of Mre11 and Rad50 genes, which was shown to be phylogenetically distinct from the canonical version of Mre11/Rad50 that are universally conserved in the three domains of life [47]. The non-canonical gene version was also found in other viruses, plasmids and a few unrelated cellular organisms including diatoms, Dictyostelium, Micromonas, Deferribacter and Clostridium. The scattered phylogenetic distribution of the non-canonical type of genes in cellular organisms suggests that the mimivirus Mre11/Rad50 gene was not derived from its host. It is more parsimonious to assume that the ancestral non-canonical gene was encoded in an ancient virus and an ancient virus-cell gene transfer gave birth to the two Mre11/Rad50 lineages (i.e., the canonical cellular and the non-canonical viral lineages) than to hypothesize an ancient gene duplication in a cellular organism followed by independent gene losses in different cellular lineages (Figure 2). Although one cannot determine the direction of this ancient gene transfer (either virus-to-cell or cell-to-virus) from the tree topology, the inferred existence of Mre11/Rad50 in an ancestral virus (prior to LUCA) is compatible with Forterre's scenario.

NAD-dependent DNA ligases, found in a minority of Megavirales, form a monophyletic group outside cellular homologs, and may be derived from an ancient virus 
world through bacteriophages [48]. In several Megavirales lineages, the ancestral NADdependent ligase was displaced by an ATP-dependent ligase from cellular organisms [48,49]. The NAD-dependent DNA ligase genes in $\mathrm{PgV}$ and $\mathrm{CeV}$ are fused with the coding region of a DNA polymerase of family X (PolX) [21,38].

Apurinic/apyrimidinic (AP) endonucleases of Megaviridae, Marseilleviridae and Entomopoxvirinae also form a monophyletic group, thus being unlikely to be recently emerged in Megavirales [50] (Figure S1A). The Entomopoxvirinae AP endonuclease genes are fused with the coding region of PolX [50].

All the currently sequenced Megaviridae genomes encode MutS homologs (MutS7 or MutS8 subfamily) [18]. MutS7 was also found in Heterocapsa circularisquama DNA virus (HcDNAV), the mitochondria of octocorals and several Epsilonproteobacteria. HcDNAV (356 kb) is distantly related to African swine fever virus based on DNA polymerase sequences [51]. MutS7 shows an atypical domain architecture with an additional C-terminal $\mathrm{HNH}$ endonuclease domain. The $\mathrm{HNH}$ domain is suggested to have the role of MutH, an endonuclease that introduces a nick in the newly synthesized DNA strand. Outside Megaviridae, MutS8 was only found in 'Candidatus Amoebophilus asiaticus', an amoeba-associated bacterium. Both of the two MutS subfamilies are only distantly related to other subfamilies such as bacterial MutS1/MutS2 and eukaryotic MutS homologs, suggesting an early divergence of the MutS subfamilies that likely predates the radiation of major eukaryotic lineages.

\section{Horizontal acquisition from eukaryotes}


In contrast to the above documented cases illustrating old origins of Megavirales DNA repair genes, there are cases of recent transfers of DNA repair genes from eukaryotes to Megavirales (Table 1). For example, the uracil DNA glycosylase (UDG) of pandoraviruses was clearly acquired from their host (Figure S1B). The same phylogenetic tree of UDGs also indicates (albeit less clearly) the horizontal acquisition of UDGs in Megaviridae and Entomopoxvirinae. Other similar cases include the 3-methyladenine (3-MeA) DNA glycosylases of Megavirus lba and Megavirus chiliensis (Figure S1C). The xeroderma pigmentosum complementation group G (XPG) protein of Emiliania huxleyi virus 86 (EhV-86) is also another case of gene transfer from its host (Figure S1D). Photolyases of Poxviridae were also acquired from eukaryotes (Figure S1E). Megavirales PolX involved multiple events of acquisition from different cellular organisms including eukaryotes [50] (Figure S1F). These observations clearly indicate that Megavirales genomes accumulated numerous DNA repair genes in the course of their evolution after the establishment of the lineages corresponding to the currently recognized viral families. Nonetheless, it should be noted that some of the Megavirales homologs for the above mentioned enzymes do not show evidence of recent gene transfer, including the UDGs of Poxviridae (but Entomopoxvirinae) and Marseilleviridae, 3-MeA DNA glycosylases of pandoraviruses and Mollivirus, and XPGs of Poxviridae. Their origins may be resolved in the future with the accumulation of more genomic data. Alternatively, the origin of these genes may be too old to be resolved by current phylogenetic methods.

\section{Conclusions}


The pangenome of the order Megavirales encodes most of the key enzymes involved in DNA repair pathways. The number of DNA repair enzymes encoded in individual genomes is positively correlated with the genome size. It should also be noted that all genes in tested Megavirales genomes show a nonsynonymous to synonymous substitution ratio below one, suggesting that most of the genes in the Megavirales pangenome are functional and contribute to virus fitness [52,53]. The repair enzymes are thus needed to maintain a large genome encoding the large number of functional genes as predicted from Drake's model. The last common ancestor of Megavirales encoded a few DNA repair enzymes including the NAD-dependent DNA ligase and the AP endonuclease, which are probably inherited from an ancient virus world. The Megavirales DSB repair genes $($ Mre11/Rad50) are also likely derived from an ancient virus world predating LUCA. For several other DNA repair genes, their origin can be traced back up to the last common ancestor of viral families (such as MutS7 of Megaviridae and XPG of Poxviridae). These suggest that the Megavirales lineages leading to the last common ancestors of viral families already possessed a relatively large genome encoding a number of genes with important functions that require DNA repair genes for maintenance. In contrast to these genes of ancient origins, many of the other key enzymes in the BER, NER and DDR pathways appear to originate from recent horizontal gene transfers from hosts. Megavirales thus gradually reinforced their DNA repair machinery, which further augments their coding capacity, in the course of more recent evolution of individual viral families. Given the long evolutionary time required to achieve the current distribution of DNA repair genes in Megavirales from its ancestor, the large genome of an extant Megavirales should not be seen as an entity that is 
rapidly expanding through rampant acquisition of genes and junk DNA, but may be seen as a functionally constrained entity like the genomes of many other extant living organisms.

\section{Acknowledgement}

We are grateful to Dr. Susumu Goto for his valuable comments on an earlier version of our manuscript. This work was in part supported by JSPS KAKENHI (Grant number 26430184), Canon Foundation (Project number 203143100025) and the Collaborative Research Program of Institute for Chemical Research, Kyoto University (Grant number 2015-125). Computation time was provided by the SuperComputer System, Institute for Chemical Research, Kyoto University. 


\section{References}

1. Iyer LM, Aravind L, Koonin EV: Common origin of four diverse families of large eukaryotic DNA viruses. J Virol 2001, 75:11720-11734.

2. Yutin N, Koonin EV: Pandoraviruses are highly derived phycodnaviruses. Biol Direct 2013, 8:25.

3. Iyer LM, Balaji S, Koonin EV, Aravind L: Evolutionary genomics of nucleo-cytoplasmic large DNA viruses. Virus Res 2006, 117:156-184.

4. Colson P, De Lamballerie X, Yutin N, Asgari S, Bigot Y, Bideshi DK, Cheng XW, Federici BA, Van Etten JL, Koonin EV, et al.: "Megavirales", a proposed new order for eukaryotic nucleocytoplasmic large DNA viruses. Arch Virol 2013, 158:2517-2521.

5. Claverie JM: Viruses take center stage in cellular evolution. Genome Biol 2006, 7:110.

6. Krupovic M, Koonin EV: Polintons: a hotbed of eukaryotic virus, transposon and plasmid evolution. Nat Rev Microbiol 2015, 13:105-115.

$* *$

An excellent opinion article in which the authors describe the evolutionary relationships among bacterial tectovirus and selfish double-stranded DNA elements of eukaryotes. Authors then described a coherent evolutionary scenario where Polintons were the first group of eukaryotic double-stranded DNA viruses that evolved from bacteriophages. Megavirales, other large eukaryotic DNA viruses and various other selfish genetic elements derived from Polintons.

7. Filee J: Route of NCLDV evolution: the genomic accordion. Curr Opin Virol 2013, 3:595-599.

8. Moreira D, Brochier-Armanet C: Giant viruses, giant chimeras: the multiple evolutionary histories of Mimivirus genes. BMC Evol Biol 2008, 8:12.

9. Takemura M, Yokobori S, Ogata H: Evolution of Eukaryotic DNA Polymerases via Interaction Between Cells and Large DNA Viruses. J Mol Evol 2015, 81:24-33.

$*$

An original research article presenting molecular evidence that suggests DNA polymerase genes evolved through horizontal gene transfer between the viral and archaeal-eukaryotic lineages. This result revives hypotheses regarding the putative role of NCLDVs in the genesis of eukaryotic nucleus.

10. Koonin EV, Krupovic M, Yutin N: Evolution of double-stranded DNA viruses of eukaryotes: from bacteriophages to transposons to giant viruses. Ann N Y Acad Sci 2015, 1341:10-24.

*

This review article described the diversity of double stranded DNA viruses of eukaryotes and assert the hypothesis stating that Megavirales along with transposons and plasmids were derived from Polintonviruses.

11. Koonin EV, Senkevich TG, Dolja VV: The ancient Virus World and evolution of cells. Biol Direct 2006, 1:29.

12. Filee J, Siguier $\mathrm{P}$, Chandler $\mathrm{M}$ : I am what I eat and I eat what I am: acquisition of bacterial genes by giant viruses. Trends Genet 2007, 23:10-15.

13. Yutin N, Wolf $\mathrm{YI}$, Koonin EV: Origin of giant viruses from smaller DNA viruses not from a fourth domain of cellular life. Virology 2014, 466-467:38-52. 
A comprehensive phylogenomic analysis of giant viruses (Mimiviruses, Pithoviruses and Pandoraviruses) in which authors systematically trace the origin of some universal cellular genes present in these viruses to test the fourth domain hypothesis.

14. Moreira D, Lopez-Garcia P: Evolution of viruses and cells: do we need a fourth domain of life to explain the origin of eukaryotes? Philos Trans R Soc Lond B Biol Sci 2015, 370:20140327.

$*$

In this review article authors explain and demonstrate how the high evolutionary rate of viruses can lead to artefactual trees supporting the fourth domain hypothesis.

15. Abergel $C$, Legendre $M$, Claverie $J M$ : The rapidly expanding universe of giant viruses: Mimivirus, Pandoravirus, Pithovirus and Mollivirus. FEMS Microbiol Rev 2015, 39:779-796.

**

An excellent review article in which authors portray the four families of giant viruses and extend the fourth domain hypothesis to postulate that each giant viral lineage evolved by reduction from unknown domains of protocellular life.

16. Raoult D, Audic S, Robert C, Abergel C, Renesto P, Ogata H, La Scola B, Suzan M, Claverie JM: The 1.2-megabase genome sequence of Mimivirus. Science 2004, 306:1344-1350.

17. Fischer MG, Allen MJ, Wilson WH, Suttle CA: Giant virus with a remarkable complement of genes infects marine zooplankton. Proc Natl Acad SciU S A 2010, 107:19508-19513.

18. Ogata H, Ray J, Toyoda K, Sandaa RA, Nagasaki K, Bratbak G, Claverie JM: Two new subfamilies of DNA mismatch repair proteins (MutS) specifically abundant in the marine environment. ISME J 2011, 5:1143-1151.

19. Santini S, Jeudy S, Bartoli J, Poirot O, Lescot M, Abergel C, Barbe V, Wommack KE, Noordeloos $A A$, Brussaard CP, et al.: Genome of Phaeocystis globosa virus PgV-16T highlights the common ancestry of the largest known DNA viruses infecting eukaryotes. Proc Natl Acad Sci U S A 2013, 110:10800-10805.

20. Moniruzzaman M, LeCleir GR, Brown CM, Gobler CJ, Bidle KD, Wilson WH, Wilhelm SW: Genome of brown tide virus (AaV), the little giant of the Megaviridae, elucidates NCLDV genome expansion and host-virus coevolution. Virology 2014, 466-467:60-70.

21. Gallot-Lavallee L, Pagarete A, Legendre M, Santini S, Sandaa RA, Himmelbauer H, Ogata H, Bratbak G, Claverie JM: The 474-Kilobase-Pair Complete Genome Sequence of CeV-01B, a Virus Infecting Haptolina (Chrysochromulina) ericina (Prymnesiophyceae). Genome Announc 2015, 3.

22. Philippe N, Legendre M, Doutre G, Coute Y, Poirot O, Lescot M, Arslan D, Seltzer V, Bertaux L, Bruley $\mathrm{C}$, et al.: Pandoraviruses: amoeba viruses with genomes up to $2.5 \mathrm{Mb}$ reaching that of parasitic eukaryotes. Science 2013, 341:281-286.

23. Antwerpen MH, Georgi E, Zoeller L, Woelfel R, Stoecker K, Scheid P: Whole-genome sequencing of a pandoravirus isolated from keratitis-inducing acanthamoeba. Genome Announc 2015, 3.

24. Legendre M, Lartigue A, Bertaux L, Jeudy S, Bartoli J, Lescot M, Alempic JM, Ramus C, Bruley C, Labadie K, et al.: In-depth study of Mollivirus sibericum, a new 30,000-y-old giant virus infecting Acanthamoeba. Proc Natl Acad Sci U S A 2015, 112:E5327-5335.

25. Legendre M, Bartoli J, Shmakova L, Jeudy S, Labadie K, Adrait A, Lescot M, Poirot O, Bertaux L, Bruley $C$, et al.: Thirty-thousand-year-old distant relative of giant icosahedral DNA viruses with a pandoravirus morphology. Proc Natl Acad Sci U S A 2014, 111:4274-4279. 
26. Sharma V, Colson P, Chabrol O, Pontarotti P, Raoult D: Pithovirus sibericum, a new bona fide member of the "Fourth TRUC" club. Front Microbiol 2015, 6:722.

27. Sharma V, Colson P, Chabrol O, Scheid P, Pontarotti P, Raoult D: Welcome to pandoraviruses at the 'Fourth TRUC' club. Front Microbiol 2015, 6:423.

28. Majji S, Thodima V, Sample R, Whitley D, Deng Y, Mao J, Chinchar VG: Transcriptome analysis of Frog virus 3, the type species of the genus Ranavirus, family Iridoviridae. Virology 2009, 391:293-303.

29. Legendre M, Audic S, Poirot O, Hingamp P, Seltzer V, Byrne D, Lartigue A, Lescot M, Bernadac A, Poulain J, et al.: mRNA deep sequencing reveals 75 new genes and a complex transcriptional landscape in Mimivirus. Genome Res 2010, 20:664-674.

30. Yanai-Balser GM, Duncan GA, Eudy JD, Wang D, Li X, Agarkova IV, Dunigan DD, Van Etten JL: Microarray analysis of Paramecium bursaria chlorella virus 1 transcription. J Virol 2010, 84:532-542.

31. Rubins KH, Hensley LE, Bell GW, Wang C, Lefkowitz EJ, Brown PO, Relman DA: Comparative analysis of viral gene expression programs during poxvirus infection: a transcriptional map of the vaccinia and monkeypox genomes. PLOS One 2008, 3:e2628.

32. Assarsson E, Greenbaum JA, Sundstrom M, Schaffer L, Hammond JA, Pasquetto V, Oseroff C, Hendrickson RC, Lefkowitz EJ, Tscharke DC, et al.: Kinetic analysis of a complete poxvirus transcriptome reveals an immediate-early class of genes. Proc Natl Acad Sci U S A 2008, 105:2140-2145.

33. Yang Z, Bruno DP, Martens CA, Porcella SF, Moss B: Genome-wide analysis of the 5' and 3' ends of vaccinia virus early mRNAs delineates regulatory sequences of annotated and anomalous transcripts. J Virol 2011, 85:5897-5909.

34. Ince IA, Boeren S, van Oers MM, Vlak JM: Temporal proteomic analysis and label-free quantification of viral proteins of an invertebrate iridovirus. J Gen Virol 2015, 96:196-205.

35. Wong CK, Young VL, Kleffmann T, Ward VK: Genomic and proteomic analysis of invertebrate iridovirus type 9. J Virol 2011, 85:7900-7911.

36. Renesto P, Abergel C, Decloquement P, Moinier D, Azza S, Ogata H, Fourquet P, Gorvel JP, Claverie JM: Mimivirus giant particles incorporate a large fraction of anonymous and unique gene products. J Virol 2006, 80:11678-11685.

37. Fischer MG, Kelly I, Foster L, Suttle CA: The virion of Cafeteria roenbergensis virus (CroV) contains a complex suite of proteins for transcription and DNA repair. Virology 2014, 466-467:82-94.

38. Redrejo-Rodriguez M, Salas ML: Repair of base damage and genome maintenance in the nucleo-cytoplasmic large DNA viruses. Virus Res 2014, 179:12-25.

39. Hou $Y$, Lin S: Distinct gene number-genome size relationships for eukaryotes and noneukaryotes: gene content estimation for dinoflagellate genomes. PLOS One 2009, 4:e6978.

40. Drake JW: A constant rate of spontaneous mutation in DNA-based microbes. Proc Natl Acad Sci U S A 1991, 88:7160-7164.

41. Lynch M: Evolution of the mutation rate. Trends Genet 2010, 26:345-352.

42. Sung W, Ackerman MS, Miller SF, Doak TG, Lynch M: Drift-barrier hypothesis and mutationrate evolution. Proc Natl Acad Sci U S A 2012, 109:18488-18492.

43. de Souza RF, Iyer LM, Aravind L: Diversity and evolution of chromatin proteins encoded by DNA viruses. Biochim Biophys Acta 2010, 1799:302-318. 
44. Leipe DD, Aravind L, Koonin EV: Did DNA replication evolve twice independently? Nucleic Acids Res 1999, 27:3389-3401.

45. Forterre P: Why are there so many diverse replication machineries? I Mol Biol 2013, 425:4714-4726.

46. Forterre P: Three RNA cells for ribosomal lineages and three DNA viruses to replicate their genomes: a hypothesis for the origin of cellular domain. Proc Natl Acad Sci U S A 2006, 103:3669-3674.

47. Yoshida T, Claverie JM, Ogata H: Mimivirus reveals Mre11/Rad50 fusion proteins with a sporadic distribution in eukaryotes, bacteria, viruses and plasmids. Virol J 2011, 8:427.

48. Yutin N, Koonin EV: Evolution of DNA ligases of nucleo-cytoplasmic large DNA viruses of eukaryotes: a case of hidden complexity. Biol Direct 2009, 4:51.

49. Filee J, Pouget N, Chandler M: Phylogenetic evidence for extensive lateral acquisition of cellular genes by Nucleocytoplasmic large DNA viruses. BMC Evol Biol 2008, 8:320.

50. Yutin N, Koonin EV: Hidden evolutionary complexity of Nucleo-Cytoplasmic Large DNA viruses of eukaryotes. Virol J 2012, 9:161.

51. Ogata H, Toyoda K, Tomaru Y, Nakayama N, Shirai Y, Claverie JM, Nagasaki K: Remarkable sequence similarity between the dinoflagellate-infecting marine girus and the terrestrial pathogen African swine fever virus. Virol J 2009, 6:178.

52. Ogata $\mathrm{H}$, Claverie JM: Unique genes in giant viruses: regular substitution pattern and anomalously short size. Genome Res 2007, 17:1353-1361.

53. Doutre G, Philippe N, Abergel C, Claverie JM: Genome analysis of the first Marseilleviridae representative from Australia indicates that most of its genes contribute to virus fitness. J Virol 2014, 88:14340-14349.

54. Fromme JC, Verdine GL: Base excision repair. Adv Protein Chem 2004, 69:1-41.

55. Kim YJ, Wilson DM, 3rd: Overview of base excision repair biochemistry. Curr Mol Pharmacol 2012, 5:3-13.

56. Setlow RB, Carrier WL: The Disappearance of Thymine Dimers from DNA: An Error-Correcting Mechanism. Proc Natl Acad Sci U S A 1964, 51:226-231.

57. Costa RM, Chigancas V, Galhardo Rda S, Carvalho H, Menck CF: The eukaryotic nucleotide excision repair pathway. Biochimie 2003, 85:1083-1099.

58. Kamarthapu V, Nudler E: Rethinking transcription coupled DNA repair. Curr Opin Microbiol 2015, 24:15-20.

59. Habraken Y, Sung P, Prakash L, Prakash S: Yeast excision repair gene RAD2 encodes a singlestranded DNA endonuclease. Nature 1993, 366:365-368.

60. Marteijn JA, Lans $\mathrm{H}$, Vermeulen $\mathrm{W}$, Hoeijmakers JH: Understanding nucleotide excision repair and its roles in cancer and ageing. Nat Rev Mol Cell Biol 2014, 15:465-481.

61. Lammens K, Bemeleit DJ, Mockel C, Clausing E, Schele A, Hartung S, Schiller CB, Lucas M, Angermuller C, Soding J, et al.: The Mre11:Rad50 Structure Shows an ATP-Dependent Molecular Clamp in DNA Double-Strand Break Repair. Cell 2011, 145:54-66.

62. Kreuzer KN: Recombination-dependent DNA replication in phage T4. Trends Biochem Sci 2000, 25:165-173.

63. Storvik KA, Foster PL: The SMC-like protein complex SbcCD enhances DNA polymerase IVdependent spontaneous mutation in Escherichia coli. J Bacteriol 2011, 193:660-669.

64. Schofield MJ, Hsieh P: DNA mismatch repair: molecular mechanisms and biological function. Annu Rev Microbiol 2003, 57:579-608. 
65. Iyer RR, Pluciennik A, Burdett V, Modrich PL: DNA mismatch repair: functions and mechanisms. Chem Rev 2006, 106:302-323.

66. Eker AP, Quayle C, Chaves I, van der Horst GT: DNA repair in mammalian cells: Direct DNA damage reversal: elegant solutions for nasty problems. Cell Mol Life Sci 2009, 66:968-980.

67. Yi C, He C: DNA repair by reversal of DNA damage. Cold Spring Harb Perspect Biol 2013, 5:a012575.

68. Eddy SR: Hidden Markov models. Curr Opin Struct Biol 1996, 6:361-365. 


\section{Box 1: DNA repair pathways}

\section{Base Excision Repair (BER)}

Most damage to bases in DNA is repaired by the BER pathway [54]. There are several variations in BER, resulting in the replacement of either a single nucleotide or a slightly longer stretch of DNA strand. A typical BER is initiated by any of several DNA glycosylases (uracil DNA glycosylase (UDG), Fpg or 3-methyladenine (3-MeA) DNA glycosylase) to remove an incorrect or damaged substrate base. This creates an abasic site, which is incised by an apurinic/apyrimidinic (AP) endonuclease. A lyase or phosphodiesterase then removes the remaining sugar, leaving a gap that will be filled by a family X DNA polymerase before a DNA ligase seals the nicked DNA strand [55].

\section{Nucleotide Excision Repair (NER)}

NER, initially described in bacteria [56] and later shown to be present in all domains of life, is the most versatile DNA repair pathway $[57,58]$. One of the key enzymes recruited in the NER pathway is the endonuclease of the eukaryotic XPG family, a single-stranded structure-specific DNA endonuclease, which cleaves single-stranded DNA during NER to excise damaged DNA $[59,60]$.

\section{Double-Strand Break (DSB) Repair}

DSBs are a major cause of genomic instability [61]. DSBs occur upon exposure of the genome to DNA-damaging agents but also emerge during normal DNA metabolic processes including replication, recombination and viral recombination-dependent DNA 
replication [62,63]. Eukaryotic/archaeal Mre11/Rad50 (and the orthologous bacterial $\mathrm{SbcD} / \mathrm{SbcC}$ ) constitute the key machinery that recognizes DSBs and bridges two DNA ends to initiate DSB repair.

\section{Mismatch Repair (MMR)}

MMR recognizes and corrects base-base mismatches and small indels introduced during normal replication, leading to 50- to 1000 -folds enhancement of replication fidelity $[64,65]$. In bacteria, MutS (MutS1) recognizes mismatches/indels and MutH, an endonuclease, introduces a nick in the newly synthesized DNA strand to start MMR. MutS homologs are ubiquitous in cellular organisms, and exhibit ancient paralogs with different functions in MMR, recombination or chromosomal stability [64].

\section{Direct Damage Reversal (DDR)}

In contrast to the sophisticated BER, NER, DSB and MMR pathways, DDR makes use of a single protein to remove lesions without incision of the sugar-phosphate backbone or base excision [66]. The reversing of UV light-induced photolesions by photolyases is one of the three major DNA repair mechanisms by DDR that have been identified to date [67]. 


\section{Figure Legends}

Figure 1. Relationship between the size of genome and the number of DNA repair genes in Megavirales. Only key enzymes involved in major DNA repair pathways are considered. DNA repair proteins were first identified in annotated Megavirales genomes through keyword searches. The resulting sequences were used to build hidden Markov model (HMM) profiles. These profiles, plus Pfam profiles for DNA repair domains, were searched against Megavirales proteomes using hmmsearch [68] to identify homologs (Evalue $<0.01$, score $>100$, and score $>5$ times the bias composition correction score).

Figure 2. A simplified phylogenetic tree showing two lineages of Mre11/Rad50 homologs and possible scenarios for the origin of the two lineages. (A) A scenario that assumes an ancestral gene duplication in a cellular organism (prior to the last universal common ancestor, LUCA). In this scenario, the two canonical and non-canonical gene lineages emerged through a gene duplication in an ancient cellular organism. The presence of the non-canonical gene in viral lineages and plasmids are explained by gene transfer from cells to viruses. This scenario is not parsimonious, because it has to assume numerous and independent losses of non-canonical genes in different cellular lineages. (B) A scenario that assumes the presence of Mre11/Rad50 in an ancient viral lineage. The ancient viral lineage may be the origin of the canonical gene lineages in cellular organisms (i.e., transfers of the viral genes to cells in agreement with Forterre's evolutionary model). In this scenario, the presence of the non-canonical genes in several cellular organisms can be readily explained by additional and later gene transfers from viruses to cells. 
Table 1. Family distribution and inferred evolutionary origin of selected Megavirales DNA repair genes.

\begin{tabular}{|c|c|c|c|c|c|}
\hline $\begin{array}{l}\text { Repair } \\
\text { pathway }\end{array}$ & Proteins & Viral families & $\begin{array}{l}\text { Recent } \\
\text { acquisition } \\
\text { from hosts }\end{array}$ & $\begin{array}{l}\text { Non-eukaryotic } \\
\text { origin }\end{array}$ & References \\
\hline \multirow[t]{6}{*}{ BER } & UDG & $\begin{array}{l}\text { Mars, Mega, Pando, } \\
\text { Pox }\end{array}$ & Ento, Pando, & $\begin{array}{l}\text { Mars, Mega*, } \\
\text { Pox (but Ento), }\end{array}$ & $\begin{array}{l}\text { Supplementary } \\
\text { figure S1B }\end{array}$ \\
\hline & $\begin{array}{l}\text { 3-MeA DNA } \\
\text { glycosylases }\end{array}$ & Mega, Molli, Pando, & Mega & Molli, Pando & $\begin{array}{l}\text { Supplementary } \\
\text { figure S1C }\end{array}$ \\
\hline & AP endonuclease & Mars, Mega, Ento & - & Mars, Mega, Ento & $\begin{array}{l}\text { [50]; } \\
\text { Supplementary } \\
\text { figure S1A }\end{array}$ \\
\hline & PolX & Mega, MpV1, Ento & $\begin{array}{l}\text { Mega (but } \mathrm{AaV}, \\
\mathrm{CeV}, \mathrm{PgV})\end{array}$ & $\begin{array}{l}\text { Ento, MpV1, } \\
\mathrm{AaV}, \mathrm{CeV}, \mathrm{PgV}\end{array}$ & $\begin{array}{l}{[50] ;} \\
\text { Supplementary } \\
\text { figure S1F }\end{array}$ \\
\hline & $\begin{array}{l}\text { NAD-dependent } \\
\text { ligase }\end{array}$ & Ento, Irido, Mega & - & Yes & {$[50]$} \\
\hline & ATP-dependent ligase & $\begin{array}{l}\text { APMVB, Asf, Mars, } \\
\text { Phyco, Pitho, Pox }\end{array}$ & Yes & - & {$[50]$} \\
\hline NER & XPG & $\begin{array}{l}\text { Asco, EhV, Irido, } \\
\text { Mars, Mega, Pox }\end{array}$ & EhV, Mega, & $\begin{array}{l}\text { Asco, Irido, } \\
\text { Mars, Pox }\end{array}$ & $\begin{array}{l}\text { Supplementary } \\
\text { figure S1D }\end{array}$ \\
\hline DSB & Mre11/Rad50 & Asco, Irido, Mega & - & Asco, Irido, Mega & [47] \\
\hline MMR & MutS7 and 8 & Mega & - & Mega & {$[18]$} \\
\hline DDR & Photolyases & Mega, Pox & Mega*, Pox & - & $\begin{array}{l}50] ; \\
\text { Supplementary } \\
\text { figure S1E }\end{array}$ \\
\hline
\end{tabular}

Names with an asterisk correspond to cases where the evolutionary origins of genes were not clear from phylogeny.

Abbreviations: Asco, Ascoviridae; Asf, Asfarviridae; Irido, Iridoviridae; Mars, Marseilleviridae; Mega, Megaviridae;

Phyco, Phycodnaviridae; Pox, Poxviridae; AaV, Aureococcus anophagefferens virus; APMVB, Acanthamoeba polyphaga moumouvirus; $\mathrm{CeV}$, Chrysochromulina ericina virus; EhV, Emiliania huxleyi virus; Ento, Entomopoxvirinae; Molli, Mollivirus sibericum; MpV1, Micromonas sp. RCC1109 virus MpV1; Pando, pandoraviruses; PgV, Phaeocystis globosa virus; Pitho, Pithovirus sibericum. 


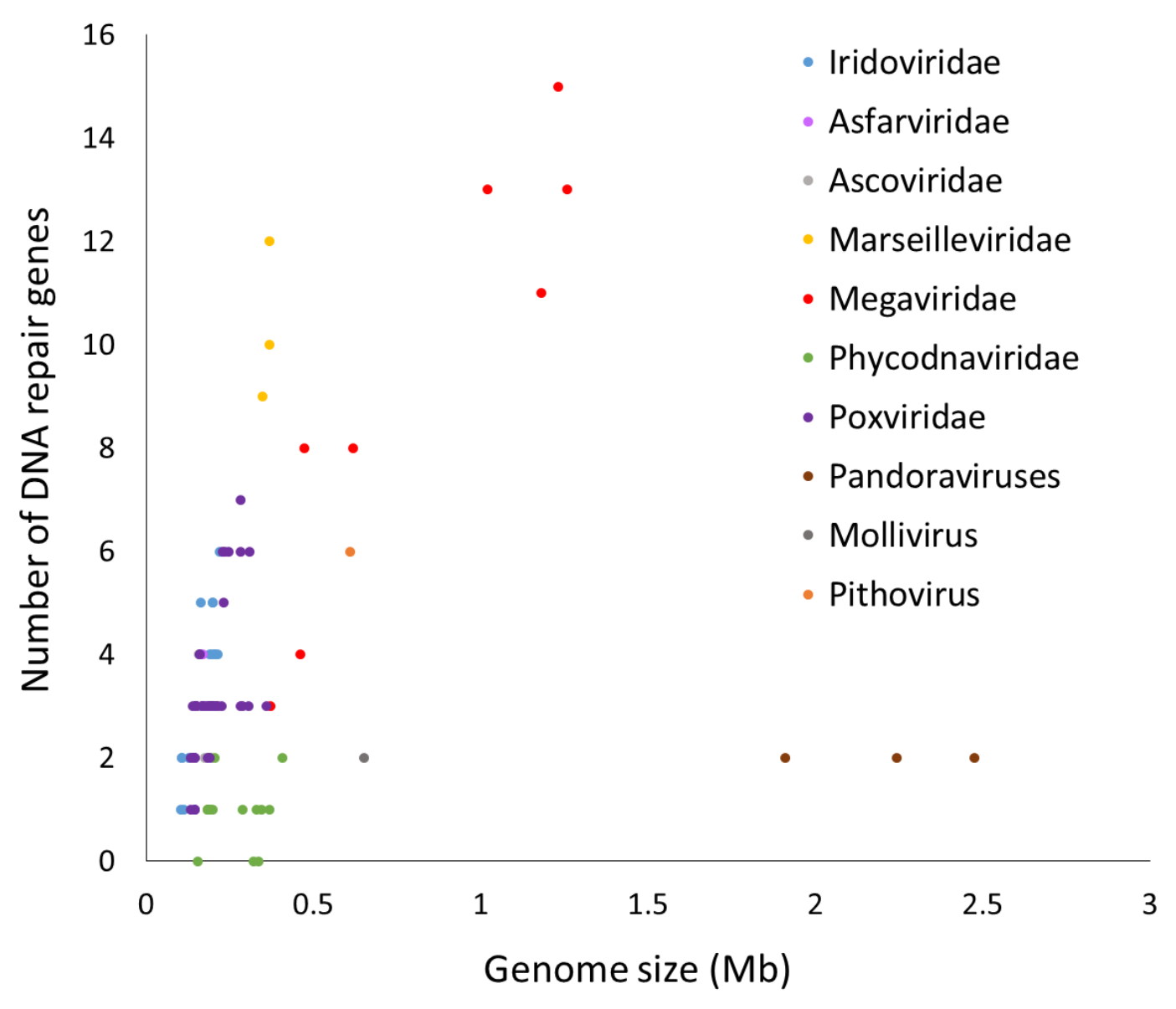


A

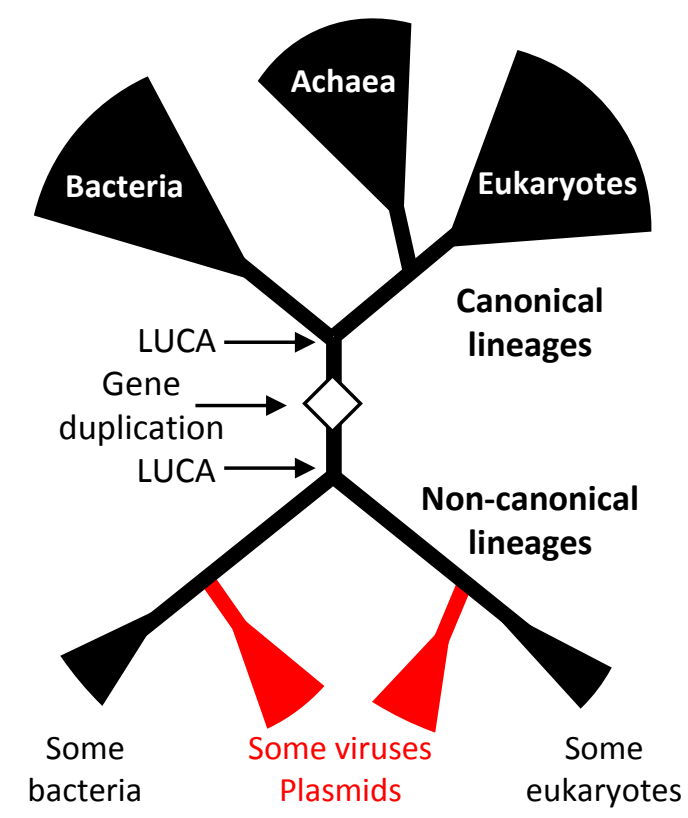

B

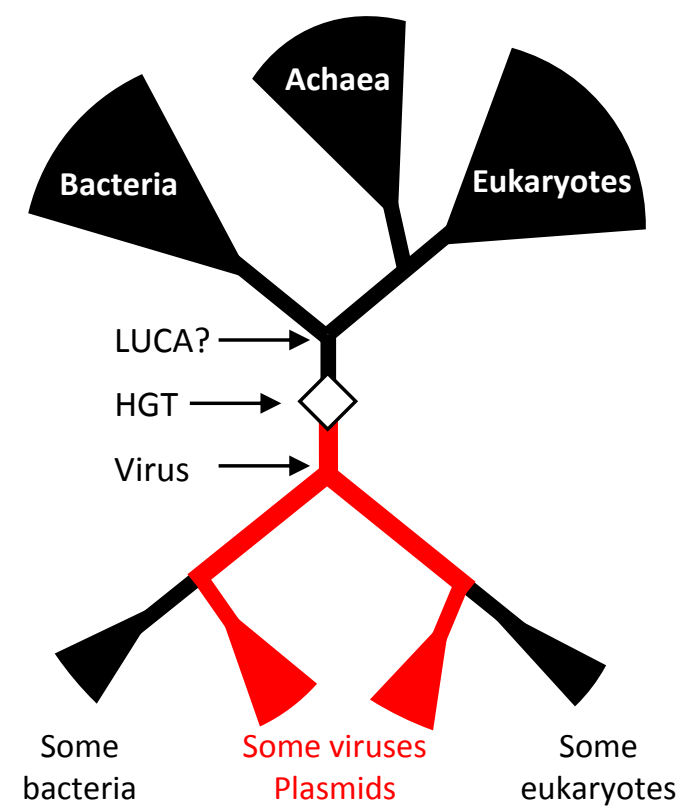


Table S1. Number of DNA repair genes in Megavirales.

\begin{tabular}{|c|c|c|}
\hline Virus name & Family & ID \\
\hline African swine fever virus & Asfarviridae & NC_001659 \\
\hline Heliothis virescens ascovirus $3 \mathrm{e}$ & Ascoviridae & NC_009233 \\
\hline Spodoptera frugiperda ascovirus $1 \mathrm{a}$ & Ascoviridae & NC_008361 \\
\hline Trichoplusia ni ascovirus $2 \mathrm{c}$ & Ascoviridae & NC_008518 \\
\hline Ambystoma tigrinum virus & Iridoviridae & NC_005832 \\
\hline Anopheles minimus irodovirus & Iridoviridae & NC_023848 \\
\hline Armadillidium vulgare iridescent virus & Iridoviridae & NC_024451 \\
\hline European catfish virus & Iridoviridae & NC_017940 \\
\hline Frog virus 3 & Iridoviridae & NC_005946 \\
\hline Infectious spleen and kidney necrosis virus & Iridoviridae & NC_003494 \\
\hline Invertebrate iridescent virus 22 & Iridoviridae & NC_023615 \\
\hline Invertebrate iridescent virus 3 & Iridoviridae & NC_008187 \\
\hline Invertebrate iridescent virus 30 & Iridoviridae & NC_023611 \\
\hline Invertebrate iridescent virus 6 & Iridoviridae & NC_003038 \\
\hline Invertebrate iridovirus 22 & Iridoviridae & NC_021901 \\
\hline Invertebrate iridovirus 25 & Iridoviridae & NC_023613 \\
\hline Lymphocystis disease virus - isolate China & Iridoviridae & NC_005902 \\
\hline Lymphocystis disease virus 1 & Iridoviridae & NC_001824 \\
\hline Singapore grouper iridovirus & Iridoviridae & NC_006549 \\
\hline Wiseana iridescent virus & Iridoviridae & NC_-015780 \\
\hline $\begin{array}{l}\text { Lausannevirus } \\
\text { nasion }\end{array}$ & Marseilleviridae & NC_015326 \\
\hline Marseillevirus marseillevirus & Marseilleviridae & NC_013756 \\
\hline Melbournevirus & Marseilleviridae & NC_025412 \\
\hline Acanthamoeba polyphaga mimivirus & Megaviridae & NC_014649 \\
\hline Acanthamoeba polyphaga moumouvirus & Megaviridae & NC_020104 \\
\hline Aureococcus anophagefferens virus & Megaviridae & NC_024697 \\
\hline Cafeteria roenbergensis virus BV-PW1 & Megaviridae & NC_014637 \\
\hline Chrysochromulina ericina virus & Megaviridae & NC_028094 \\
\hline Megavirus chiliensis & Megaviridae & NC_016072 \\
\hline Megavirus lba & Megaviridae & NC_020232 \\
\hline Phaeocystis globosa virus & Megaviridae & NC_021312 \\
\hline Acanthocystis turfacea Chlorella virus 1 & Phycodnaviridae & NC_008724 \\
\hline Bathycoccus sp. RCC1105 virus BpV1 & Phycodnaviridae & NC_014765 \\
\hline Ectocarpus siliculosus virus 1 & Phycodnaviridae & NC_002687 \\
\hline Emiliania huxleyi virus 86 & Phycodnaviridae & NC_007346 \\
\hline Feldmannia species virus & Phycodnaviridae & NC_011183 \\
\hline Micromonas pusilla virus $12 \mathrm{~T}$ & Phycodnaviridae & NC_020864 \\
\hline Micromonas sp. RCC1109 virus MpV1 & Phycodnaviridae & NC_014767 \\
\hline Ostreococcus lucimarinus virus 1 & Phycodnaviridae & NC_014766 \\
\hline Ostreococcus lucimarinus virus OlV5 & Phycodnaviridae & NC_020852 \\
\hline Ostreococcus tauri virus 1 & Phycodnaviridae & NC_013288 \\
\hline Ostreococcus tauri virus 2 & Phycodnaviridae & NC_014789 \\
\hline Ostreococcus virus OsV5 & Phycodnaviridae & NC_010191 \\
\hline Paramecium bursaria Chlorella virus 1 & Phycodnaviridae & NC_000852 \\
\hline
\end{tabular}




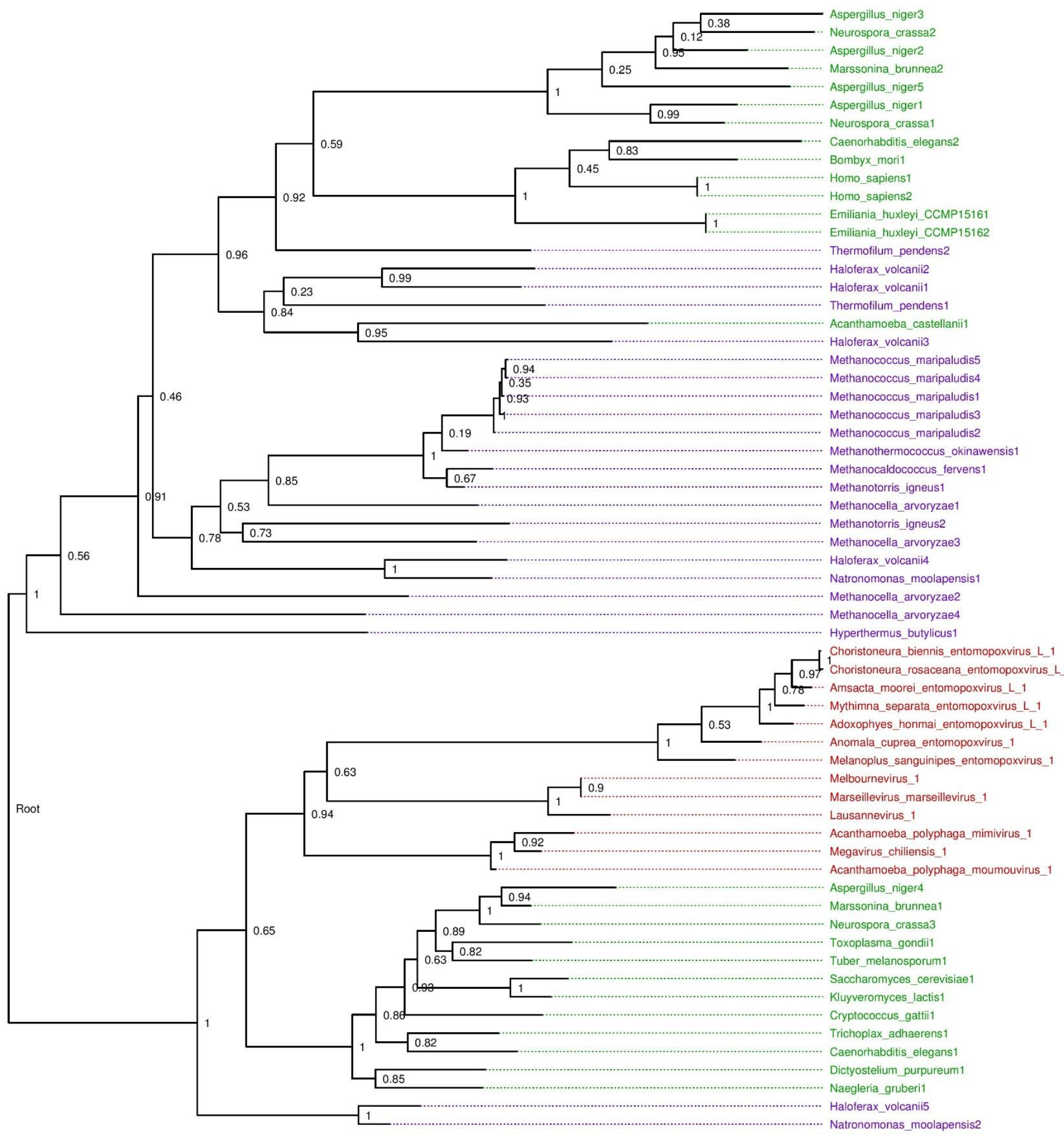




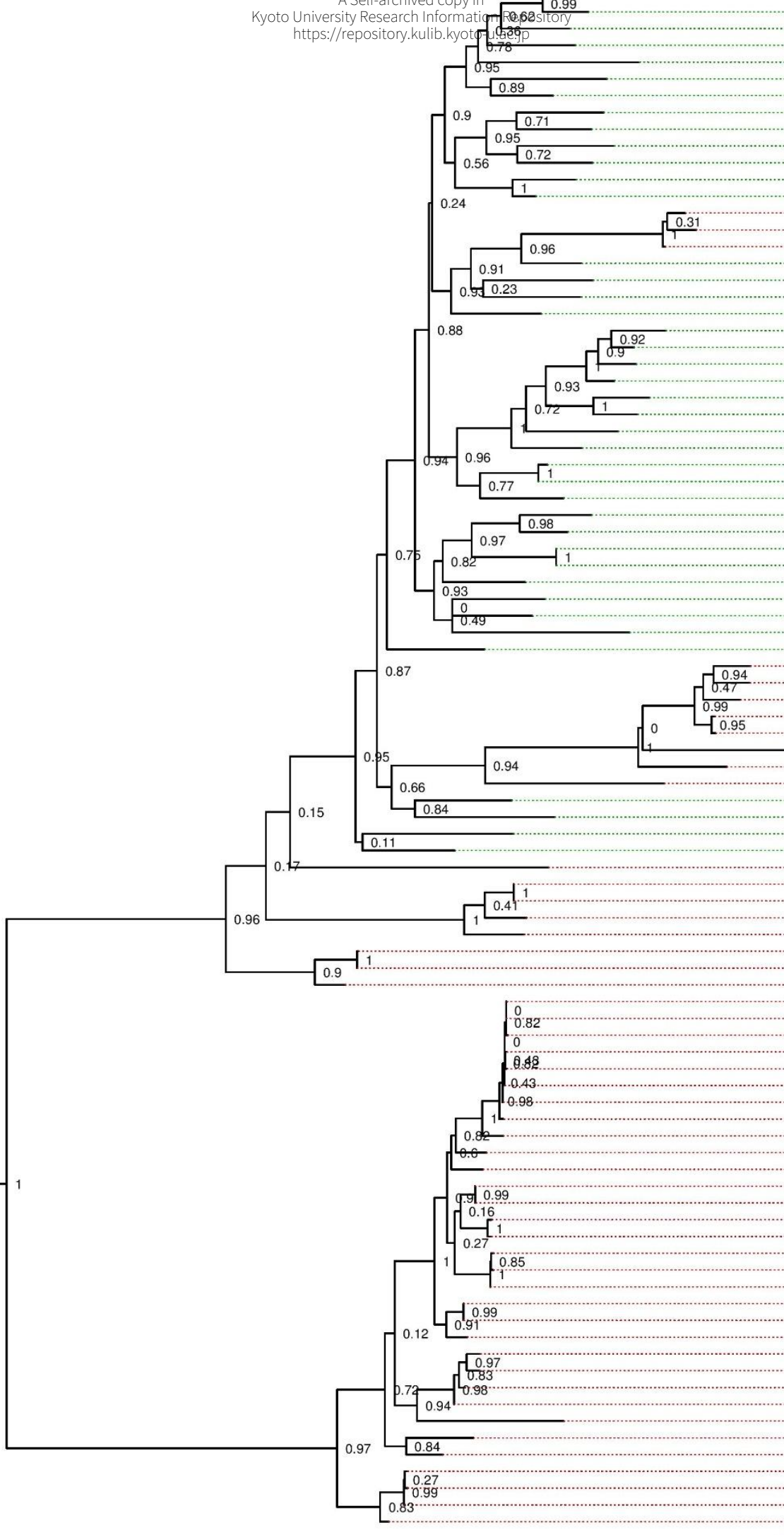

Neinhardtil

Tha

Theudonana2

Phytophthora_sojae 1

Acanthamoeba_castellanii5

Acanthamoeba_castellanii2

Pandoravirus_dulcis_1

Pandoravirus_inopinatum_1

Pandoravirus_salinus_1

Acanthamoeba_castellanii3

Naegleria_gruberi1

Acanthamoeba_castellanii4

Chondrus_crispus 1

Tuber_melanosporum 1

Marssonina_brunnea1

Neurospora_crassa 1

Aspergillus_niger1

Kluyveromyces lactis 1

Saccharomyces_cerevisiae 1

Phanerochaete_carnosa1

Cryptococcus gattii1

Homo_sapiens 1

Homo_sapiens2

Trichoplax_adhaerens1

Leishmania_major1

Trypanosoma cruzi1

Caenorhabditis_elegans 1

Caenorhabditis_elegans2

Emiliania_huxleyi_CCMP15161

Acanthamoeba_castellanii7

Acanthamoeba_castellanii 1

Acanthamoeba_castellanii6

Galdieria_sulphuraria1

Mythimna_separata_entomopoxvirus_L_1

Adoxophyes honmai entomopoxvirus L 1

Amsacta_moorei_entomopoxvirus_L_1

Choristoneura_rosaceana_entomopoxvirus_L

Choristoneura_biennis_entomopoxvirus_L_1

Melanoplus_sanguinipes_entomopoxvirus_1

Anomala_cuprea_entomopoxvirus_1

Chrysochromulina_ericina_virus_1

Dictyostelium_purpureum1

Trichomonas vaginalis1

Toxoplasma gondii 1

Paramecium_tetraurelia1

Pithovirus_sibericum_1

Megavirus_lba_1

Megavirus_chiliensis_1

Acanthamoeba polyphaga moumouvirus 1

Acanthamoeba polyphaga mimivirus 1

Melbournevirus_1

Lausannevirus_1

Camelpox_virus_1

Taterapox_virus

Variola_virus_1

Ectromelia_virus_1

Monkeypox virus Zaire-96-I-16_1

Vaccinia_virus 1

Cowpox virus 1

Raccoonpox_virus_1

Yoka_poxvirus_1

Swinepox_virus_1

Cotia_virus_SPAn232_1

Deerpox virus W-848-83

Deerpox virus W-1170-84 1

Rabbit fibroma virus 1

Myxoma_virus_1

Lumpy_skin_disease_virus_NI-2490_1

Sheeppox_virus_1

Goatpox_virus_Pellor_1

Tanapox_virus_1

Yaba-like_disease_virus_1

Yaba monkey tumor virus 1

Bovine papular stomatitis virus 1

Parapoxvirus red deer HL953

Orf virus 1

Pseudocowpox_virus_

Nile_crocodilepox_virus_

Molluscum_contagiosum_virus_subtype_1_1

Squirrelpox_virus_1

Penguinpox virus 1

Pigeonpox virus 1

Fowlpox virus 1

Canaryox virus_1

1. Aciduliprofundum_boonei3

- Aciduliprofundum_boonei4 Pyrococcus_abyssi1

Aciduliprofundum_boonei2

Aciduliprofundum boonei1

Acidianus_hospitalis1

Korarchaeum cryptofilum1

Candidatus_Korarchaeum_cryptofilum1

Methanocella_arvoryzae 1

Thermofilum_pendens 1

Hyperthermus_butylicus 1

Thermoproteus_tenax 1

Archaeoglobus sulfaticallidus 1

0.86

Ignicoccus hospitalis1

Natronomonas moolapensis 1

Haloferax volcanii1 


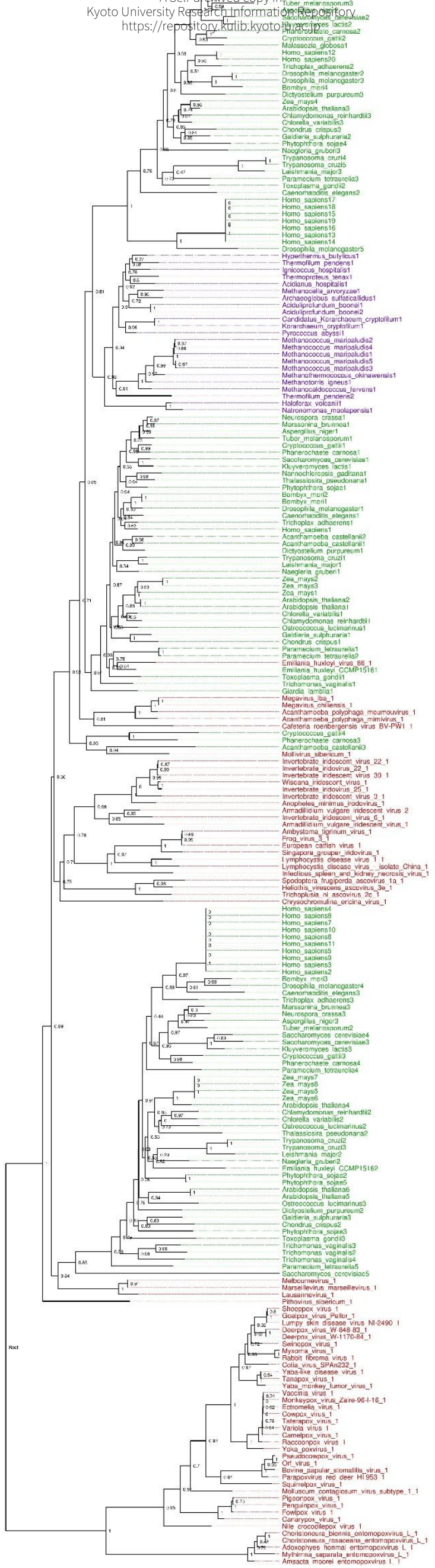


A Self-archived copy in $\quad \cdots$ Homo_sapiens3

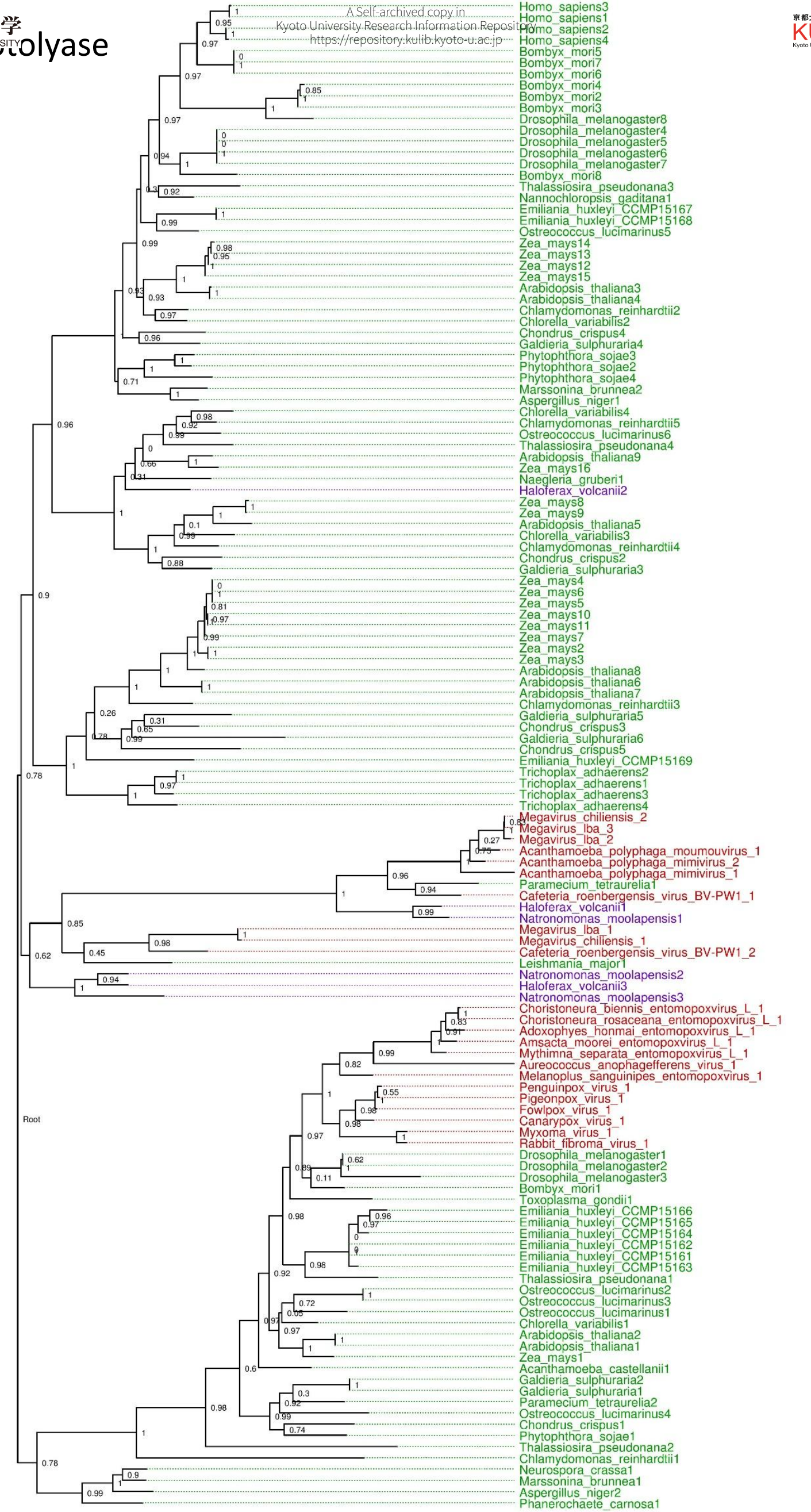


Supplementary Figure S1. Phylogenetic trees of amino acid sequences corresponding to (A) AP endonuclease, (B) UDG, (C) 3-MeA DNA glycosylase, (D) XPG, (E) photolyase and (F) PoIX. Sequences from Megavirales, eukaryotes and archaea are included. B,C,D and E are maximum likelihood phylogenies reconstructed using the ete toolkit package (Huerta-Cepas et al. 2010) with the workflow "mafft_ensi-trimal02-prottest_default-raxml". The models selected were PROTGAMMALG $(B, D)$ and PROTGAMMAVT $(C, E)$. A and $F$ are calculated by Bayesian inference with the CAT-GTR infinite mixture model (Lartillot and Philippe 2004) (4 chains were used and stopped when the "maxdiff" was less than 0.1; 1000 first trees were burned and the consensus phylogeny was build using every remaining trees). Statistical support at node is given as SH-like values (B,C,D and $E$ ) or posterior probabilities ( $A$ and $F$ ). Number at scale bar indicate the number of substitutions per site. These phylogenetic trees are midpoint rooted. Red: Megavirales, Green: Eukaryotes, Purple: Archaea.

\section{References:}

Huerta-Cepas J, Dopazo J, Gabaldón T. 2010. ETE: a python Environment for Tree Exploration. BMC Bioinformatics 11:1.

Lartillot N, Philippe H. 2004. A Bayesian mixture model for across-site heterogeneities in the amino-acid replacement process. Mol. Biol. Evol. 21:1095-1109. 